\title{
Pengadaan Bahan Baku Porduk Kopi Ready to Drink Pada Coffee Shop di Kota Bandar Lampung
}

Annisa Fitria , Dayang Berlianab dan Nuni Anggrainic

aProdi Agribisnis Pangan Politeknik Negeri Lampung, Indonesia, email: annisafitrihasibuan@polinela.ac.id

bProdi Agribisnis Pangan Politeknik Negeri Lampung, Indonesia, email: dayang@polinela.ac.id

cProdi Agribisnis Pangan Politeknik Negeri Lampung, Indonesia, email: nuni.anggraini@polinela.ac.id

\begin{tabular}{|c|c|}
\hline Article Info & Abstrak \\
\hline $\begin{array}{l}\text { Article history: } \\
\text { Received } 8 \text { Januari } 2021 \\
\text { Received in revised from } 23 \text { Januari } 2021 \\
\text { Accepted 28 Januari } 2021 \\
\end{array}$ & \multirow{3}{*}{$\begin{array}{l}\text { Coffee shops are currently still constrained by the procurement of raw materials, } \\
\text { assurance of product quality continuity, inadequate supply, and the accuracy of } \\
\text { delivery time. This study aims to understand the characteristics of coffee } \\
\text { entrepreneurs and the accuracy of the procurement of coffee shop coffee raw } \\
\text { materials in Bandar Lampung. This research was conducted from May to October } \\
\text { 2020. Sampling has done by snowball technique for } 10 \text { coffee shops. The data } \\
\text { analysis method used is descriptive qualitative method. The results showed that } \\
\text { coffee shop entrepreneurs in Bandar Lampung are coffee shop entrepreneurs aged } \\
20-29 \text { years, have a higher education level, had experience less than two years, } \\
\text { and coffee shop entrepreneurs have of } 6 \text { workers in average. Procurement of raw } \\
\text { materials has met the criteria for the accuracy of timing and quantity. However, it is } \\
\text { necessary to increase the accuracy of the place, price, type, quantity, and quality, } \\
\text { so that the sustainability of the coffee shop business in Bandar Lampung can be } \\
\text { maintained. }\end{array}$} \\
\hline & \\
\hline $\begin{array}{l}\text { Keywords: } \\
\text { Coffee } \\
\text { Coffee Shop } \\
\text { Procurement } \\
\text { Raw Materials }\end{array}$ & \\
\hline
\end{tabular}

\section{Pendahuluan}

Indonesia merupakan produsen kopi terbesar ke-empat setelah Brazil, Vietnam, dan Kolombia dengan volume produksi mencapai 654 ribu ton pada tahun 2017 atau setara dengan 6,84 persen dari produksi kopi global (International Coffee Organization, 2018). Faktor yang memengaruhi ekspor kopi Indonesia adalah harga kopi internasional (Fatimah, 2018). Harga kopi internasional ditentukan oleh Bursa London untuk robusta dan Bursa New York untuk arabika, mengakibatkan peningkatan harga kopi di Bursa belum tentu terjadinya peningkatan harga di tingkat petani kopi. Marlina (2014) menyatakan petani kopi lebih memilih menjual kopinya ke pedagang pengumpul dan pasar domestik dengan pertibangan jarak, harga, dan kekerabatan.

Konsumsi kopi Indonesia mengalami peningkatan dari tahun 2014-2017. Berdasarkan data (International Coffee Organization, 2018) perkembangan jumlah konsumsi nasional tahun 20142018 jumlah konsumsi nasional sebesar 265.000 ton per tahun dan mengalami peningkatan pada tahun 2017-2018 sebesar 282.000 ton per tahun. Peningkatan konsumsi kopi di Indonesia harus diikuti peningkatan produksi kopi. Berdasarkan Badan Pusat Statistik (2018) produksi rata-rata kopi Provinsi Lampung menempati urutan ke tiga terbesar 114,030 ton setelah Sumatra Utara sebesar 262,03 ton dan Sumatra Selatan sebesar 117,37 ton.

Provinsi Lampung sebagai produksi kopi tertinggi berpeluang untuk dijadikan agroindustri berbasis pengolahan kopi yang memiliki peluang untuk dikembangkan. Menurut Noer et al., (2012) agroindustri merupakan salah satu bentuk industri hilir yang berbahan baku produk pertanian dan menekankan pada produk olahan dalam suatu perusahaan atau industri. Haryanto (2012) menyatakan perkembangan industri hulu hingga hilir dapat menciptakan lapangan pekerjaan, peningkatan pendapatan petani, karena memiliki produk yang bernilai jual tinggi, tersedianya lahan yang cukup untuk produksi, dan kebutuhan masyarakat akan produk olahan terpenuhi.

Saat ini industri kopi berbentuk kedai kopi yang di awali dengan hobi minum kopi dan kemudian menyukai hobi tersebut menjadi usaha. Seiring dengan perkebangan zaman kedaikedai kopi berkembang menjadi coffee shop modern. Coffee shop merupakan salah satu jenis cafe yang menjual berbagai jenis kopi dan biasanya menjual makanan ringan sebagai pendamping kopi (Tashim et al., 2019). Coffee shop dapat dijumpai hampir di seluruh kota, terutama kotakota besar dan kota yang sudah populer dengan wisata kulinernya salah satunya adalah Kota Bandar Lampung. Persaingan bisnis antar coffee shop menyebabkan perkembangan teknologi dan berorientasi pada kepuasan konsumen, sehingga penjual harus menjual kualitas kopi yang bermutu, harga terjakau, dan bahan baku terpenuhi tepat pada waktunya.

Kondisi saat ini usaha coffee shop di Bandar Lampung masih terkendala dengan pengadaan bahan baku yang berkualitas. Biaya pengiriman bahan baku kopi di kirim dengan melalui jalur darat dan masih dalam satu Provinsi Lampung dapat menambah biaya produksi yang berdampak pada penurunan kualitas. Sumber bahan baku kopi memiliki peranan penting dalam keberlangsungan usaha coffee shop. Perlu dilakukan pengelolaan yang tepat terkait pengadaan bahan baku. Menurut Assauri (1999) proses pengadaan bahan baku harus memiliki enam 
kriteria yaitu tepat tempat, tepat waktu, tepat jenis, tepat kuantitas, tepat kualitas, tepat harga, sehingga bahan baku tetap terjaga. Penentuan jumlah, ketersediaan bahan baku harus sesuai dengan kebutuhan coffee shop, karena kopi yang disimpan terlalu lama, akan menurunkan kualitas. Bahan baku yang sangat banyak atau bahan baku yang sangat sedikit dapat berpengaruh terhadap biaya dan keuntungan usaha (Kusuma et al., 2020). Usaha yang memiliki bahan baku terlalu besar akan membutuhkan biaya investasi yang besar, tetapi persediaan yang kurang berdampak pada penurunan tingkat pelayanan perusahaan (Ghozali dan Setiawan 2012).

Pengadaan bahan baku akan menentukan efektivitas tingkat produksi, menurunkan biaya produksi, harga jual produk yang dihasilkan dapat bersaing dan dapat memenuhi permintaan konsumen, sehingga tepat pada waktunya Alicia (2011) dalam (Tumijo et al., 2015). Oleh karena itu penting bagi pengusaha coffee shop untuk menjaga pengadaan bahan baku kopi secara tepat, untuk menghidari kerugian. Bedasarkan uraian latar belakang topik yang menarik untuk dikaji adalah pengadaan bahan baku produk kopi ready to drink pada coffee shop di kota Bandar Lampung. Tujuan dari penelitian ini adalah (1) mengetahui karakteristik pengusaha coffee shop di Bandar Lampung; 2) mengetahui ketepatan pengandaan bahan baku berdasarkan kriteria tepat tempat, tepat waktu, tepat jenis, tepat kuantitas, tepat kualitas, tepat harga.

\section{Metode}

Penelitian yang digunakan adalah pendekatakan kualitatif. Menurut Kusuma \& Joka (2020) penelitian kualitatif dikategorikan interpretative inquiry sebab banyak menggunakan faktor subjektif, yang terdiri informan, subjek penelitian maupun peneliti itu sendiri. Penelitian ini berfokus pada ketepatan pengandaan bahan baku coffee shop di kota Bandar Lampung.

Penelitian ini dilakukan di Kota Bandar Lampung. Pemilihan lokasi dilakukan secara purposif dengan pertimbangan Kota Bandar Lampung merupakan pusat perkembangan industri coffee shop. Penelitian ini dilaksanakan Mei - Oktober 2020. Jenis data yang digunakan dalam penelitian ini adalah data kualitatif. Penelitian kualitatif merupakan prosedur penelitian yang menghasilkan data tertulis atau lisan orang dan perilaku yang dapat diamati Bogdan dan Taylor dalam Moleong (2010). Sumber data yang digunakan dalam penelitian ini adalah data primer. Data primer merupakan data yang didapat langsung dari sumber asli (tidak melalui perantara). Pengambilan sampel untuk coffee shop teknik snowball sebanyak 10 coffee shop yang terdiri dari Coffee shop coffee campus, 555 boba, teraz caffee, dotuku kopi, dijou, mogue'coffee, kia coffee, tanoki,tuya, dan cafe kiyo.

Metode pengumpulan data dalam penelitian ini terdiri dari (1) Wawancara dengan informan yang telah dipilih dengan memakai teknik wawancara mendalam. Wawancara berlangsung dengan menyusun daftar pertanyaan yang memuat pokok-pokok pikiran masalah yang akan diteliti; (2) Observasi yang dilakukan dengan melihat, mengamati , mencermati, dan merekam perilaku secara sistematis untuk suatu tujuan tertentu; (3) Dokumentasi dengan melakukan pengumpulan data-data yang berhubungan dengan kebutuhan kopi di coffee shop; (4) Studi Pustaka dilakukan untuk memperoleh teori melalui buku-buku, publikasi artikel dan artikel media masa terpercaya.

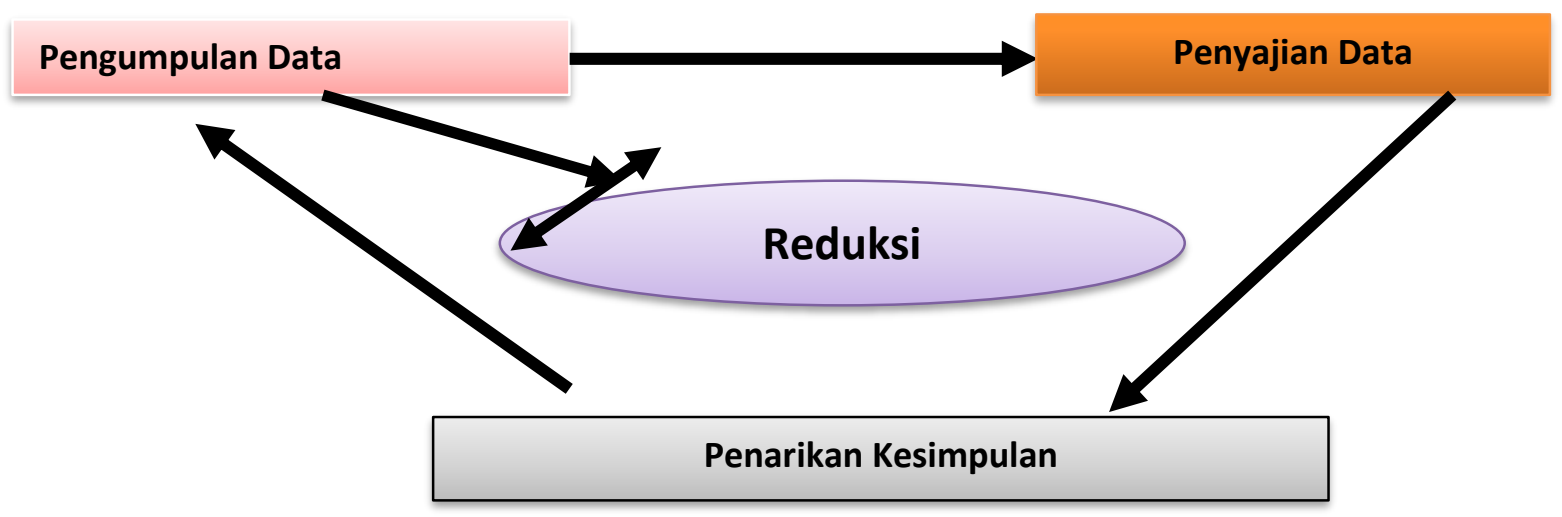

Gambar 1 Kerangka Metodologi Penelitian Sumber: Kusuma \& Joka (2020)

Metode analisis data yang digunakan untuk mengetahui proses pengadaan bahan baku pada penelitian ini adalah metode deskriptif kualitatif. Dalam menganalisis data kualitatif terdapat beberapa tahap yaitu melalui pengumpulan data dan reduksi data.Analisis data pada penelitian kualitatif dapat berupa kata-kata, kalimat-kalimat, atau narasi-narasi baik yang 
diperoleh dari wawancara mendalam maupun observasi Kusuma \& Joka (2020) . Gambar 1 merupakan kerangka metodologi penelitian.

Analisis deskriptif yaitu dengan menggambarkan proses pengadaan bahan baku berupa pelaksanaan enam kriteria tepat yakni tepat tempat, tepat waktu, tepat jenis, tepat kuantitas, tepat kualitas, tepat harga (Assauri, 1999). Kriteria proses pengadaan bahan baku kopi dapat dilihat pada Tabel 1 .

Tabel 1. Kriteria Pengadaan Bahan Baku Kopi

\begin{tabular}{ll}
\hline Komponen Pengadaan Bahan Baku & \multicolumn{1}{c}{ Kriteria Harapan } \\
\hline Waktu & $\begin{array}{l}\text { Pengadaan bahan baku minimal dilakukan 1 kali } \\
\text { dalam sebulan }\end{array}$ \\
Tempat & Bahan baku dekat dengan usaha \\
Kualitas & Serangga hidup tidak ada \\
& Biji kopi berbau busuk dan atau kapang tidak ada \\
& Kadar air maksimal 12,5 persen \\
& Kadar kafein robusta 2,2-2,7\%. \\
& persen, arabika 1,1-1,5\% persen. \\
& Kandungan asam arabika 5,5-8\% \\
& Kandungan 7-10\%. \\
Kuantitas & Tersedianya kopi tercukupi \\
Jenis & Kopi lokal arabika dan robusta \\
Harga & Harga kopi arabika Rp.215.000/kg \\
& Harga kopi robusta Rp.160.000/kg \\
\hline
\end{tabular}

Selanjutnya proses analisis data akan dilakukan dengan membandingkan kriteria komponen ketepatan pengadaan bahan baku kopi dengan kondisi saat penelitian.

\section{Hasil dan Pembahasan}

\subsection{Karakteristik Pengusaha coffee shop}

Setiap pengusaha memiliki karakteristik usaha yang berbeda tergantung dari jenis usaha yang dijalankan. Karakteristik usaha meliputi pengalaman usaha dan tenaga kerja yang digunakan. Seluruh karakteristik ini menunjukkan kemampuan pengusaha dalam mengembangkan usahanya, Rata-rata karakteristik usaha pada Tabel 1 . Rata-rata pengalaman usaha pada pengusaha coffee shop adalah 1,2 tahun. Hal ini menunjukkan bahwa usaha coffee shop merupakan usaha yang sedang berkembang saat ini. Berdasarkan Tabel 2 rata-rata jumlah tenaga kerja yang digunakan pada usaha coffee shop adalah 6 orang, yang tersebar pada coffee shop dijou sebesar 30 orang. Kondisi ini menunjukkan adanya perbedaan yang cukup besar antara coffee shop dalam sistem upah dibayarkan secara bulanan.

Tabel 2. Rata-rata pengalaman usaha dan jumlah tenaga kerja 10 coffee shop Coffee Shop Di Kota Bandar Lampung

\begin{tabular}{llc}
\hline No. & Karakteristik Usaha & Rata-rata 10 cofee shop \\
\hline 1 & Pengalaman usaha (tahun) & 1,2 \\
2 & Tenaga kerja (orang) & 6 \\
\hline Sumber: Data Primer diolah, 2020
\end{tabular}

Tabel 3 menunjukkan pengusaha coffee shop mayoritas ada pada usia produktif yaitu 2029 tahun sebanyak 7 orang. Sedangkan yang paling sedikit adalah usia diatas 30 tahun yaitu sebanyak 3 orang. Sedangkan yang paling sedikit adalah usia diatas 30 tahun yaitu sebanyak 3 orang. Pengusaha coffee shop pada usia produktif memiliki semangat yang tinggi dalam mengisi waktunya untuk hal yang dapat menopang kebutuhan hidup pengusaha. Penelitian Nkuah et al., (2013) pemilik usaha produktif memiliki akses yang lebih besar dalam akses pembiayaan. Selain itu, keahlian dan penilaian terhadap usia yang produktif usaha yang dirintis lebih akurat. Oleh sebab itu, lebih banyak pengusaha usia produktif yang melakukan usaha coffee shop.

Tabel 4 menunjukkan bahwa pengusaha coffee shop mayoritas memiliki tingkat pendidikan perguruan tinggi. Pendidikan yang yang tinggi mengakibatkan pemikiran para pengusaha mengikuti kegiatan organisasi dan pelatihan pengembangan usaha coffee shop. Dengan mengikuti kegiatan organisasi dan pelatihan pengusaha dapat meningkatkan skala usaha dan meningkatkan omset usaha coffee shop. Senada dengan penelitian Pandula (2011) Pendidikan merupakan faktor penting dalam akses dan partisipasi pada pembiayaan formal, karena pemilik usaha yang berpendidikan tinggi memiliki kemampuan yang lebih baik untuk mencari informasi 
keuangan dan rencana usaha serta membangun relasi dengan institusi keuangan. Pemilik usaha yang lebih berpendidikan akan memiliki skill manajerial yang lebih baik, sehingga kemampuannya untuk berpartisipasi dalam sumber pembiayaan formal juga meningkat.

Tabel 3 Umur Pengusaha Coffee Shop Di Kota Bandar Lampung

\begin{tabular}{cccc}
\hline No. & Umur (tahun) & Jumlah Responden (orang) & Persentase $\%$ \\
\hline 1 & $20-29$ & 7 & 70 \\
2 & $30-39$ & 1 & 10 \\
3 & $40-49$ & 0 & 0 \\
4 & $50-59$ & 2 & 20 \\
5 & $>60$ & 0 & 0 \\
Jumlah & & 10 & 100 \\
\hline
\end{tabular}

Sumber: Data Primer diolah, 2020

Tabel 4 Tingkat Pendidikan Pengusaha Coffee Shop Di Kota Bandar Lampung

\begin{tabular}{cccc}
\hline No. & Tingkat Pendidikan & Jumlah Responden (orang) & Persentase \% \\
\hline 1 & Tidak Tamat SD & 0 & 0 \\
2 & SD & 0 & 0 \\
3 & SMP & 0 & 0 \\
4 & SMA & 3 & 30 \\
5 & PT & 7 & 70 \\
Jumlah & & 10 & 100 \\
\hline
\end{tabular}

Sumber: Data Primer diolah, 2020

\subsection{Pengadaan Bahan Baku Produk Kopi Ready To Drink Pada Coffee Shop Di Kota Bandar Lampung}

Proses pengadaan bahan baku berupa pelaksanaan enam tepat yakni tepat tempat, tepat waktu, tepat jenis, tepat kuantitas, tepat kualitas, tepat harga (Assauri ,1999). Suryaningrat (2016) menjelaskan bahwa bahan baku merupakan faktor terpenting untuk menopang kegiatan pengolahan dalam sistem agroindustri.

\subsection{Tepat waktu}

Berdasarkan Tabel 5 waktu pengadaan bahan baku 10 coffee shop telah tepat waktu yaitu pengadaan bahan baku dilakukan minimal 1 bulan sekali sebanyak 100 persen. Dalam waktu satu bulan coffee shop coffee campus, teraz café, dotuku kopi, dijou, mogue'coffee, kia coffee, tanoki, tuya, dan kopi kiyo dalam 1 bulan melakukan pemesanan 4 kali. Coffee shop 555 boba melakukan pemesanan bahan baku satu kali dalam sebulan. Kusuma et al., (2020) menyatakan waktu pengadaan bahan baku disesuaikan dengan kebutuhan bahan baku dalam proses produksi. Waktu ketersediaan bahan baku perlu diperhatikan agar kuantitas dan kualitas bahan baku yang digunakan baik, sehingga coffee shop tidak mengalami kendala pasokan bahan baku.

\subsection{Tepat Tempat}

Kriteria tempat pengadaan bahan baku berdasarkan pada coffee shop memperoleh bahan baku untuk kegiatan produksi. Tabel 5 menunjukkan 80 persen lokasi memperoleh bahan baku dekat dengan usaha yaitu coffee campus, dotuku kopi, dijou, mogue'coffee, kia coffee, tanoki, tuya, dan kopi kiyo. Coffee shop di Bandar Lampung melakukan kemitraan dengan petani-petani kopi di Lampung Barat untuk memperoleh bahan baku kopi. Petani kopi sebagai mitra memiliki syarat- syarat yang harus dipenuhi unuk bergabung ke kemitraan coffee shop, hal tersebut tertuang dalam sebuah kontrak perjanjian. Didalam kontrak perjanjian tersebut perusahaan mitra coffee shop yaitu membeli hasil produksi petani kopi dan mitra petani kopi melaksanakan kegiatan produksi diwajibkan menjual seluruh produksinya. Saptana (2005) dan Syahyuti (2007) dalam Daryanto (2013) model sub kontrak merupakan perusahaan dapat melakukan kemitraan dengan petani yang memproduksi kebutuhan bahan baku yang diperlukan oleh perusahaan sebagai bagian dari bahan baku produksinya kontrak. Coffee shop 555 boba dan teraz café endapatkan pasokan bahan baku kopi dari luar lampung dan impor (luar negeri), sehingga belum tepat dalam pemenuhan bahan baku. Sumber bahan baku yang jauh menyebabkan penurunan pada kualitas kopi yang dihasilkan. 


\subsection{Tepat Kualitas}

Kualitas kopi yang digunakan sebagai bahan baku dalam coffee shop di daerah penelitian dapat berpengaruh terhadap produk kopi yang dihasilkan. Tabel 5 menunjukkan 90 persen coffee shop telah tepat kualitas yaitu serangga yang hidup pada biji kopi tidak ada, tidak ada bau busuk pada biji kopi, kadar air maksimal 12,5 persen, kadar kafein 2,2-2,7 persen untuk robusta, 1,1-1,5\% untuk arabika. Coffee shop yang telah tepat kualitas yaitu coffee campus, teraz café, 555 boba, dotuku kopi, kia coffee, kopi kiyo, mogue'coffee, tuya dan tanoki. Coffee shop dijou belum tepat kualitas kopi, karena memiliki kadar air kopi hingga 13 persen. Peneltitan ini sesuai dengan Muchtadi (2010) menyatakan kualitas produk kopi ditentukan dari cita rasa kopi yang dilihat dari kandungan kafein, kadar air, dan berat biji kopi tersebut.

\subsection{Tepat Kuantitas}

Berdasarkan tabel 5 kuantitas bahan baku kopi pada 10 coffee shop selalu tercukupi hingga saat ini. Coffee shop di Bandar Lampung telah melakukan kegiatan pengadaan bahan baku dengan tepat kuantitas. Rata-rata kuantitas bahan baku kopi yang dibutuhkan coffee shop adalah $10 \mathrm{~kg}$ selama satu bulan. Jumlah bahan baku diharapkan mampu mencukupi target ketersediaan bahan baku pada coffee shop, sehingga dapat mencukupi target output yang ingin dicapai oleh coffee shop. Senada dengan penelitian Anggraeni et al., (2017) kuantitas atau jumlah bahan baku yang dipakai akan berpengaruh terhadap jumlah output yang dihasilkan.

Tabel 5 Pengadaan bahan baku kopi pada coffee shop di Bandar Lampung

\begin{tabular}{|c|c|c|c|}
\hline $\begin{array}{c}\text { Komponen } \\
\text { Pengadaan } \\
\text { Bahan Baku }\end{array}$ & Kriteria Harapan & Realisasi & $\begin{array}{l}\text { Persentase Realisasi } \\
\text { Berdasarkan } \\
\text { Kriteria Harapan (\%) }\end{array}$ \\
\hline Waktu & $\begin{array}{l}\text { Pengadaan bahan baku minimal } \\
\text { dilakukan } 1 \text { kali } \\
\text { dalam sebulan }\end{array}$ & $\begin{array}{l}\text { Pengadaan Bahan baku coffe } \\
\text { shop telah } \\
\text { dilakukan minimal } 1 \text { bulan } \\
\text { sekali. }\end{array}$ & 100 \\
\hline Tempat & Bahan baku dekat dengan usaha & $\begin{array}{l}\text { Lokasi memperoleh bahan baku } \\
\text { dekat dengan usaha } \\
8 \text { coffee shop }\end{array}$ & 80 \\
\hline Kualitas & $\begin{array}{l}\text { Serangga hidup tidak ada } \\
\text { Biji kopi berbau busuk dan atau } \\
\text { kapang tidak ada } \\
\text { Kadar air maksimal } 12,5 \text { persen } \\
\text { Kadar kafein robusta } 2,2-2,7 \% \text {. } \\
\text { persen, arabika } 1,1-1,5 \% \text { persen. } \\
\text { Kandungan asam arabika } 5,5-8 \% \\
\text { Kandungan } 7-10 \% \text {. }\end{array}$ & $\begin{array}{l}\text { Lokasi memperoleh bahan baku } \\
\text { dekat dengan usaha } \\
8 \text { coffee shop }\end{array}$ & 80 \\
\hline Kuantitas & Tersedianya kopi tercukupi & $\begin{array}{l}\text { Ketersediaan bahan baku ter } \\
\text { tercukupi }\end{array}$ & 100 \\
\hline Jenis & Kopi lokal arabika dan robusta & $\begin{array}{l}\text { Terdapat } 2 \text { jenis kopi arabika dan } \\
\text { robusta pada } 9 \text { coffee } \\
\text { Shop }\end{array}$ & 90 \\
\hline Harga & $\begin{array}{l}\text { Harga kopi arabika Rp. } 215.000 / \mathrm{kg} \\
\text { Harga kopi robusta Rp. } 160.000 / \mathrm{kg}\end{array}$ & $\begin{array}{l}\text { Harga bahan baku kopi arabika } \\
\text { Rp. } 215.000 / \mathrm{kg} \text { dan } \\
\text { arabika } \\
\text { Rp. } 160.000 \text { pada } 8 \text { coffee shop. }\end{array}$ & 80 \\
\hline
\end{tabular}

\subsection{Tepat Jenis}

Jenis kopi yang digunakan 90 persen yaitu arabika dan robusta. coffee shop coffee campus, teraz café, mogue'coffee, kia coffee, tanoki hanya menggunakan jenis bahan baku kopi robusta. Coffee shop dotuku kopi, dijou, tuya, dan kiyo menggunakan jenis kopi arabika dan robusta. coffee shop boba 555 boba menggunakan jenis kopi thai coffee. Berdasarkan tabel 590 persen coffee shop terdapat jenis kopi robusta, hal ini dikarenakan kopi robusta memiliki pasar yang lebih strategis karena mengandung antioksi dan kafein tinggi. Penelitian Suwarmini (2017) menyatakan kopi robusta dapat dipadukan dengan bahan campuran lain seperti kopi arabika, coklat, gula aren dan susu, sehingga rasa dari kopi robusta tersebut menjadi lebih disukai oleh konsumen. 


\subsection{Tepat Harga}

Harga bahan baku merupakan harga beli bahan baku yang harus dikeluarkan coffee shop dengan tujuan memenuhi kebutuhan bahan baku untuk memproduksi kopi. Harga bahan baku kopi dari pemasok kepada 10 coffee shop berbeda-beda. Harga bahan baku kopi dari pemasok ke coffee shop berbeda-beda dikarenakan perbedaan tempat pembeliaan bahan baku. Tabel 5 menunjukan 80 persen telah tepat harga dalam pembeliaan bahan baku kopi. Rata-rata harga kopi untuk arabika Rp.215.000/kg dan Robusta Rp. 160.000 pada coffee shop coffee campus, dotuku kopi, dijou, mogue'coffee, kia coffee, tanoki, tuya, dan kopi kiyo 20 persen yaitu coffee shop 555 boba dan teraz belum tepat dalam penentuan harga. Anggraeni et al., (2017) menyatakan biaya-biaya didalam pembelian bahan baku ditentukan oleh harga bahan baku.dan proses pengangkutan. Biaya yang dikeluarkan menjadi besar karena harga untuk pengadaan bahan baku sangat tinggi.

\section{Simpulan}

Beradasarkan hasil penelitian dapat disimpulkan karakteristik pegusaha coffee shop di Bandar Lampung adalah pengusaha coffee shop berusia produktif yaitu 20-29 tahun, memiliki tingkat pendidikan perguruan tinggi, pengalaman pengusaha coffee shop kurang dari dua tahun, dan pengusaha coffee shop memiliki rata-rata tenaga kerja 6 orang. Pengadaan bahan baku 10 coffee shop sudah memenuhi kriteria tepat waktu dan tepat kuantitas. Namun perlu peningkatan dari sisi ketepatan tempat, harga, jenis, kuantitas, dan kualitas, sehingga kebelangsungan usaha coffee shop di Bandar Lampung tetap terjaga.

\section{Pustaka}

Anggraeni. S.T.,D.A.H.Lestari.,Y.Indriani. 2017. Keragaan Agroindustri Tempe Anggota Primkopti Kabupaten Pesawaran. Jurnal Imu-Imu Agribisnis 5(3):275-282.

Assauri. 1999. Manajemen Produksi Dan Operasi. Revisi. Jakarta: Lembaga Penerbit Fakultas Ekonomi Universitas Indonesia.

Badan Pusat Statistik [BPS]. Statistik Indonesia 2018. Indonesia.

Daryanto,A., Saptana. 2013. Dinamika Kemitraan Usaha Agribisnis Berdayasaing Dan Berkelanjutan. Bogor: Pusat Sosial Ekonomi Pertanian, Badan Penelitian dan Pengembangan Pertanian dan Kementrian Pertanian.

Fatimah WS. 2018. Analisis daya saing dan faktor-faktor yang mempengaruhi volume ekspor kopi Indonesia ke Amerika Serikat, Jerman, dan Jepang [skripsi]. Bogor (ID) : Institut Pertanian Bogor.

Ghozali I. 2012. Aplikasi Analisis Multivariate Dengan Program IBM SPSS 20. Semarang: Badan Penerbitan Universitas Diponegoro.

Haryanto. B. 2012. Prospek Tinggi Bertanam Kopi. Yogyakarta (ID): Pustaka Baru Press.

International Coffee Organization [ICO]. 2018. Disappearance (Consumption) in Selected Importing Countries. http://www.ico.org/historical/1990 onwards/PDF/4b- disappearance.pdf.

Kusuma. D.L.G., dan U. Joka. 2020. "Analisis Pengelolaan Penjualan Penyambung (Entres) Kopi Berdasarkan Penerapan Social Oriented, Kebun Induk Kopi Robusta, Desa Sai, Kecamatan Pupuan." Agrimor 5(2): 28-31.

Kusuma.E.W., S.Widjaya., S. Situmorang. 2020. "Analisis Pengadaan Bahan Baku Dan Nilai Tambah Agroindustri Keripik Ubi Kayu Di Kecamatan Way Jepara Kabupaten Lampung Timur." Jurnal Imu-Ilmu Agribisnis 8(1): 39-47. https://jurnal.fp.unila.ac.id/index.php/JIA/article/view/4339/3116.

Marlina L. 2014. Analisis ekonomi kopi rakyat dan peranannya terhadap perekonomian wilayah Kabupaten Lampung Barat Provinsi Lampung [Tesis]. Bogor (ID) : Institut Pertanian Bogor.

Moleong L. J. 2010. Metodologi Penelitian Kualitatif. Bandung: Remaja Rosda karya.

Muchtadi. 2010. Ilmu Pengetahuan Bahan Pangan. Bogor: Alfabeta CV.

Nkuah, J. Kofi, J.Paul, and Tanyeh Kala. 2013. "Financing Small and Medium Enterprises ( Smes ) in Ghana: Challenges and Determinants in Accessing Bank Credit." International Journal of Research in social sciences 2(3): 12-25.

Noer, I., Fitriani, F., \& Agus, A. 2012. The Coffee Market Integration in Lampung Province. Jurnal Ilmiah Esai, 6 No. 1(Januari 2012).

Pandula, G. 2011. "An Empirical Investigation of Small and Medium Enterprises." Access to Bank Finance: The Case of an Emerging Economy. Proceedings of ASBBS 18(10): 255-73.

Suryaningrat dan I. Bagus. 2016. "Raw Material Procurement on Agroindustrial Supply Chain Management: A Case Survey of Fruit Processing Industries in Indonesia." Agriculture and Agricultural Science Procedia 9: 253-57. http://dx.doi.org/10.1016/j.aaspro.2016.02.143. 
Suwarmini. N.N.,S.Mulyani.,I.G.A.L.,Triani.2017. Pengaruh Blending Kopi Robusta Dan Arabika Terhadap Kualitas Seduhan Kopi. Jurnal Rekayasa dan Manajemen Agroindustri 5 (3) 2017: 85-92. ISSN: 2503-488X

Tashim. M., M. Ihsan., dan A.S. Slamet. 2019. "Pengaruh Kualitas Produk Dan Kualitas Pelayanan Terhadap Kepuasan Konsumen (Studi Kasus Pada Coffee Shop Di Kota Bogor).” Jurnal Manajemen dan Organisasi 10(2): 118-32.

Tumijo, Roni, Saharia,K., dan D. Howara. 2015. "Manajemen Persediaan Bahan Baku Pada Industri Kopi ‘Bumi Mutiara' di Kota Palu.” Jurnal Agrotekbis 3(5): 668-79. 